\title{
Making Indian Healthcare Market a Global Medical Tourism Destination
}

\author{
${ }^{1}$ Dr. Rajendra Mishra, ${ }^{2}$ Kumar Shailesh. \\ ${ }^{\text {I} A s s o c i a t e ~ P r o f e s s o r, ~ T h e ~ B u s i n e s s ~ S c h o o l, ~ J a m m u ~ U n i v e r s i t y, ~ J a m m u ~(I n d i a) ~}$ \\ ${ }^{2}$ Research Scholar Jammu University
}

\begin{abstract}
Medical Tourism in India is budding as an exponential growth of 25\%-30\% annually. Medical Tourism (also called medical travel, health tourism or global healthcare) is the practice of traveling abroad to get hold of healthcare services. Typically, by traveling abroad patients not only save a considerable amount of money but also receive world-class service. There are different opinions as to whether medical tourism is still a promising industry or had been considered firmly established. The industry is being followed and promoted by several trustworthy organizations, including the Medical Tourism Association (MTA), the Deloitte Center for Health Solutions, and the Joint Commission International. The MTA is an industry group actively involved in promoting the Medical Tourism industry, above all through its publication. The Deloitte Center is a research arm of the global accounting firm on healthcare. The JCI is a division of the Joint Commission which is involved in accrediting health care facilities outside the United States. National Accreditation board for hospitals (NABH) is responsible as Indian regulatory body for medical travel in India. India's medical tourism is dominated by the private sector from the corporate houses. Medical Tourism in India has $80 \%$ hospital managed by private sector, which is ultimately invigorating and making India a global medical Tourism destination.
\end{abstract}

Keywords: medical tourism, medical travel, inbound demand, outbound demand

\section{Medical Tourism:}

Travel trips to a foreign destination for medical treatment are Medical tourism. Certainly, for less serious procedures such as dentistry and certain forms of cosmetic surgery and orthopedic surgery, there could be the opportunity to include some pre-or post- vacation activities. If so, there are facilitators and health-travel planners available to provide such services. For those dealing with more serious surgeries, it will not be very easy to turn such a trip into a dream vacation. Some companies, such as the International Hotel Group, do provide facilities that focus on recovery needs as well as leisure recovery. And there are recovery retreats that provide the patient with high-end services (Gasparoni, 2007).

Medical tourism is a growing sector in India. India's medical tourism sector is expected to experience an annual growth rate of $30 \%$, making it a Rs. 9,500-crore industry by 2015. Estimates of the value of medical tourism to India go as high as $\$ 2$ billion a year by 2012 . India is quickly becoming a hub for medical tourists seeking quality healthcare at an affordable cost. Nearly 450,000 foreigners sought medical treatment in India last year with Singapore not too far behind and Thailand in the lead with over a million medical tourists. As the Indian healthcare delivery system strives to match international standards the Indian healthcare industry will be able to tap into a substantial portion of the medical tourism market. Already 17 Indian hospitals have been accredited by the Joint Commission International (JCI). Accreditation and compliance with quality expectations are important since they provide tourists with confidence that the services are meeting international standards. Reduced costs, access to the latest medical technology, growing compliance to international quality standards and ease of communication all work towards India's advantage.

It is not uncommon to see citizens of other nations seeking high quality medical care in the US over the past several decades; however in recent times the pattern seems to be reversing. As healthcare costs in the US are rising, price sensitivity is soaring and people are looking at medical value travel as a viable alternative opportunity. In the past the growth potential of the medical travel industry in India has been hindered by capacity and infrastructure constraints but that situation is now changing with strong economic progress in India as well as in other developing nations. With more and more hospitals receiving JCI accreditations outside the US, concerns on safety and quality of care are becoming less of an issue for those choosing to travel for medical treatment at an affordable cost. The combined cost of travel and treatment in India is still a fraction of the amount spent on just medical treatment alone in western countries.

In order to attract foreign patients many Indian hospitals are promoting their international quality of healthcare delivery by turning to international accreditation agencies to standardize their protocols and obtain the required approvals on safety and quality of care. 


\section{Driving Factors of Medical Tourism in India:}

1 Exorbitant healthcare costs in industrialized nations.

2 Long waiting lists for surgery in countries offering socialized healthcare.

3 Favorable currency exchange rates in foreign countries resulting in low cost surgery.

4 Proven safety of healthcare in select developing nations.

5 International accreditation of hospitals in developing countries.

6 Rapidly improving technology and standards of care in many countries

7 Ease and affordability of international travel connectivity

8 Relaxation in government regulations.

9 Burgeoning population and government's national health policy for increasing expenditure on healthcare.

10 Transformation of industry from unorganized to organized roadway

11 Ayurveda and naturopathy of treatment and exorbitant natural heritage is making global patients to combine Medical and Tourism.

(Source website: $\underline{w w . m e d i n e t i n d i a . c o m})$

Cost comparison among leading destinations:

\begin{tabular}{|l|l|l|l|l|}
\hline Procedures & USA & UK & Thailand & India \\
\hline Open heart surgery & 40,000 & 23,000 & 8,500 & 6,000 \\
\hline Bone marrow transplant & $2,50,000$ & $1,50,000$ & $\ldots \ldots \ldots$ & 22,000 \\
\hline Knee replacement & 25,000 & 14,000 & 8,000 & 6,000 \\
\hline $\begin{array}{l}\text { Body contouring } \\
\text { Liposuction }\end{array}$ & 20,000 & 10,000 & 4,000 & 2,500 \\
\hline
\end{tabular}

(Source: Apollo Chennai and its facilitators)

\section{Healthcare in India:}

The feature of Indian health care system is run by the constituent states and territories of India. The Constitution charges every state with "raising of the level of nutrition and the standard of living of its people and the improvement of public health as among its primary duties". The National Health Policy was endorsed by the Parliament of India in 1983 and updated in 2002. ${ }^{[1]}$ However, the government sector is understaffed and underfinanced; poor services at state-run hospitals force many people to visit private medical practitioners. Government hospitals, some of which are among the best hospitals in India, provide treatment at taxpayer expense. Most essential drugs are offered free of charge in these hospitals. Government hospitals provide treatment either free or at minimal charges. For example, an outpatient card at AIIMS (one of the best hospitals in India) costs a onetime fee of rupees 10 (around 20 cents US) and thereafter outpatient medical advice is free. In-hospital treatment costs depend on financial condition of the patient and facilities utilized by him but are usually much less than the private sector. For instance, a patient is waived treatment costs if he is below poverty line. Another patient may seek for an air-conditioned room if he is willing to pay extra for it. The charges for basic in-hospital treatment and investigations are much less compared to the private sector. The cost for these subsidies comes from annual allocations from the central and state governments. Primary health care is provided by city and district hospitals and rural primary health centers (PHCs). These hospitals provide treatment free of cost. Primary care is focused on immunization, prevention of malnutrition, pregnancy, child birth, postnatal care and treatment of common illnesses. Patients who receive specialized care or have complicated illnesses are referred to secondary (often located in district and taluk headquarters) and tertiary care hospitals (located in district and state headquarters or those that are teaching hospitals).

In recent times India has eradicated mass famines; however the country still suffers from high levels of malnutrition and disease especially in rural areas. Water supply and sanitation in India is also a major issue in the country and many Indians in rural areas lack access to proper sanitation facilities and safe drinking water. However, at the same time, India's health care system also includes entities that meet or exceed international quality standards. The medical tourism business in India has been growing in recent years and as such India is a popular destination for medical tourists who receive effective medical treatment at lower costs than in developed countries.

\section{Healthcare Infrastructure:}

The Indian healthcare industry is growing at a rapid swiftness and is expected to become a US $\$ 280$ billion industry by 2020 . The Indian healthcare market was anticipated at US\$35 billion in 2007 and is expected to reach over US $\$ 70$ billion by 2012 and US $\$ 145$ billion by 2017- According to the Investment Commission of India the healthcare sector has experienced exceptional growth of 12 percent per annum in the last 4 years. Rising income levels and a growing elderly population are all factors that are driving this growth. In addition, changing demographics, disease profiles and the shift from chronic to lifestyle diseases in the country has led to increased spending on healthcare delivery. Even so, the vast majority of the country suffers from a poor standard 
of healthcare infrastructure which has not kept up with the growing economy. Despite having centers of excellence in healthcare delivery, these facilities are limited and are inadequate in meeting the current healthcare demands. Nearly one million Indians die every year due to inadequate healthcare facilities and 700 million people have no access to specialist care and $80 \%$ of specialists live in urban areas. In order to meet manpower shortages and reach world standards India would require investments of up to $\$ 20$ billion over the next 5 years. Forty percent of the primary health centers in India are understaffed. According to World Health Organization (WHO) statistics, there are over 250 medical colleges in the modern system of medicine and over 400 in the Indian system of medicine and homeopathy (ISM\&H). India produces over 250,000 doctors annually in the modern system of medicine and a similar number of ISM\&H practitioners, nurses and Para professionals ${ }^{*}$ Better policy regulations and the establishment of public private partnerships are possible solutions to the problem of manpower shortage. India faces a huge need gap in terms of availability of number of hospital beds per 1000 population. With a world average of 3.96 hospital beds per 1000 population India stands just a little over 0.7 hospital beds per 1000 population. Moreover, India faces a shortage of doctors, nurses and paramedics that are needed to propel the growing healthcare industry.

India is now looking at establishing academic medical centers (AMCs) for the delivery of higher quality care with leading examples of The Manipal Group \& All India Institute of Medical Sciences (AIIMS) already in place. As incomes rise and the number of available financing options in terms of health insurance policies increase, consumers become more and more engaged in making informed decisions about their health and are well aware of the costs associated with those decisions. In order to remain competitive, healthcare providers are now not only looking at improving operational efficiency but are also looking at ways of enhancing patient experience overall. India has approximately 600,000 allopathic doctors registered to practice medicine. This number however, is higher than the actual number practicing because it includes doctors who have immigrated to other countries as well as doctors who have died. India licenses 18,000 new doctors a year.

\section{Demand Factors Leading To Inbound Medical Tourism \\ Availability of specialized medical treatment:}

Indian is a well known place for Ayurvedic and natural system of cure. The availability of specialized medical treatment is the initial reason for the emergence of medical tourism. Ancient Greek patients could travel from all over the Mediterranean to health spas which treated some conditions that could not be effectively treated at home. It is no different in modern societies. To treat certain diseases, people will spend money and time traveling to other places. In the last century, with their advanced medical technologies, the United States and Europe became the center of the healthcare world. Persons came to the United States for higher quality treatment than they could receive in their home country. Although medical technologies have been improving quickly in the other countries, we often hear that some well-known individuals, often athletes and political dignitaries, come to the U.S. seeking treatment because the United States is still leading the world in certain medical areas, such as sports injuries, cancer/oncology, orthopedic, cardiovascular, and cosmetic treatments. Since medical tourists usually pay more than domestic patient, many U.S. health facilities expanded their marketing to attract international patients and developed international patient departments. Several U.S. states have been especially active in promoting medical travel to their health facilities. Apollo, Fortis and Medanta, Max healthcare etc are recognized India as medical tourism destinations for certain specialty medical treatments. Some resources: In its 2008 report on medical tourism, Deloitte suggested that in 2008 there would be more than 400,000 non-U.S. residents that would receive care in the United States and spend almost $\$ 5$ billion for health services. International patients currently make up almost $3.5 \%$ of all inpatient procedures performed in the U.S. By 2011, Deloitte suggested that those numbers could rise to as much as 800,000 patients annually (Deloitte, 2009). McKinsey \& Co. a global consultancy firm reported much lower estimates of medical travel, on the order of 60,000 to 85,000 inpatients per year.

(Source: www.bharatbook.com 2008).

Approximately 150,000 patients are visiting India per year for medical treatments .These included 5,000 to 10, 000 US patients seeking non-US treatment. The lower estimates are due to a much stricter definition of the medical travel market. Needless to say, the two reports vary widely. However, even this study believed the Indian market potential to be in the range of 500,000 to 700,000 per year if payers covered medical travel. The most common medical treatments sought abroad are dentistry, cosmetic surgery, orthopedic surgery, and some cardiac procedures.

Income and wealth: The inbound demand for specialized medical treatment, which is normally quite expensive, is primarily from international patients, who are in the upper strata of income and wealth. For these patients, the cost of treatment is much less significant than the availability of the requisite medical procedure. Health insurance is not a factor for this group. They often come to the India despite having a national health insurance program. 


\section{Macroeconomic Conditions:}

Since income and wealth are significant demand variables, the state of the global economy is an important factor. In the face of the current slow global recovery from the recent recession, there has been a decline in inbound medical tourism. On the other hand, a poor economy can be a stimulus to outbound medical travel as patients who lose their jobs or health insurance seek lower costs.

\section{The Quality of Treatment:}

The inbound demand is largely for services provided in world class health facilities that can provide the full array of services needed by the patient. Especially for surgical procedures, both pre-operative and post-operative care is of very high quality. These facilities are typically highly accredited by the Joint Commission and National Accreditation Board for Hospitals $(\mathrm{NABH})$ inbound patients can use them with a high degree of confidence. The medical treatments are usually provided with an extensive array of amenities.

\section{Demand Factors Leading To Outbound Medical Tourism}

Higher Cost of Medical Treatment:

Although U.S. hospitals attract a large number of international patients by their high-end medical technologies, they are also facing a serious problem, that is, many domestic patients go abroad seeking less expensive medical treatment. According to one study, U.S. patients who have hip replacement surgery in India or Costa Rica will save approximately $75 \%$ of cost, compared to the prices that patients could get in the U.S. (Horowitz, 2007). The Deloitte Center (2008) reported on World Bank research by Mattoo and Nathindran (2005) that estimated price differences for 15 surgical procedures frequently used in outbound programs. The prices vary widely by countries, so the prices in the table are average. When extraordinary travel and insurance costs are added, the relative cost advantage for medical tourism is 28 to 88 percent, depending on the location and procedure. With the price advantage, many Asian and Latin American countries have become destinations for medical tourism. Approximately 900,000 to 1.2 million foreign patients traveled to hospitals in Thailand. In Bangkok's prestigious Bumrungrad International Hospital, 58,000 U.S. patients sought treatment in their facilities in 2005, which increased to 64,000 Americans the following year. Singapore benefited with the increase in medical tourists from 270,000 in 2004 to 410,000 foreign patients annually.

It is estimated that this will increase to a million patients by 2012. Latin America, particularly Costa Rica and Panama, are fast becoming tourist spots for medical travelers with close to 150,000 foreign patients seeking healthcare in Costa Rica in 2006. Due to its close proximity to the U.S., Mexico has become a top medical tourism destination with 40,000 to 80,000 .

(Source: www.health-tourism.com/medical-tourism/statistics/ )

Long Wait Times: A report of May 2008 McKinsey and Company report indicates that $15 \%$ of medical travelers seek faster medical services. The medical services delivery systems in many developed countries are overburdened and patients have to wait a long time to see a doctor or specialist, even longer ones for general surgeries, orthopedics, or cardiology. In Britain and parts of North America, for example, the waiting time for a hip replacement can be a year or more, while in India a patient can begin treatment shortly after arrival (Muddle Feb. 2008).

The Health Insurance Factor: The lower cost of these surgical procedures is very attractive to those who are uninsured. In the U.S., there are an estimated 47 million persons without health insurance and 120 million without dental coverage. The use of medical tourism programs can save money when compared to U.S costs. The impact of the recent health care reform legislation must be monitored as to its effect on outbound demand. Visiting the Home Country:

Many immigrants have no problem seeking medical treatment abroad. U.S. residents originating in places such as India, China, Korea, and various Latin American countries are comfortable in an environment where they know the language and culture. Often, they have close relatives with whom to stay both before and after their medical treatment.

Potential Revenue Losses: To US providers of healthcare, the potential losses from outbound medical travel could be very significant. Deloitte reports that US residents spent $\$ 2.1$ billion to 2.4 billion for overseas medical care in 2008. Moreover, assuming a 3\% annual medical cost inflation, the amount is projected to be between $\$ 30.3$ billion and $\$ 79.5$ billion by 2017 (Underwood and Makadon 2007).

\section{Issues impacting outbound Medical Tourism:}

\section{Service Quality as a Supply Factor:}

Receiving safe and high quality medical care is the primary issue for patients considering medical tourism as an alternative treatment. When patients choose other countries instead of the U.S. for medical care, they don't just consider the price. Patients also have to consider the quality of medical care that the international medical facilities provide because medical standards may vary widely from one medical care facility to another and from one country to another. It is important to know about assurances that a medical care organization has publicly committed to safe, quality patient care. The Joint Commission International (JCI) was launched by the Joint 
Commission in 1999 after a growing demand for a resource to effectively evaluate quality and safety (Deloitte 2008). JCI standards are developed with the input of experts from around the world to assess and accredit in more than 30 countries. JCI has accredited nearly 260 organizations in countries throughout the globe. (Timmons, 2009). Several other organizations, such as the International Society for Quality in Health Care (ISQUA), the National Committee for Quality Assurance (NCQA), the International Organization for Standardization (ISO), and the European Society for Quality in Healthcare (ESQH), have taken steps to ensure that medical tourism facilities provide the highest-quality clinical care. The number of accredited facilities has been steadily increasing which gives outbound patients many more options. Accreditation is particularly important because it evaluates the most significant factors and concerns that patients should consider when seeking medical care outside their home country. Though accreditation is important, it should not be the only decision making factor in choosing a medical care organization. Patients should take time to communicate directly with the hospital and with the physician that will be responsible for their care. To reduce overall risks, despite the accreditation process, American patients traveling abroad would be wise to do their own research before signing up for surgery overseas. Communication issues as well as cultural differences might also affect qualitative patient care and should not be overlooked (Retzlaff, 2008). Care coordination for patients returning home is another dimension of quality that is central to a host organizations performance. Many U.S.-based opponents of medical tourism worry that patients who receive treatment abroad may not receive proper followup care when they return to their home country. As a result, care plans that facilitate the handoff from overseas providers to providers at the patients home are critical, since domestic providers are often hesitant to take on complicated and open cases from unknown providers - let alone care from a foreign one (www.deloitte.com, 2008).

\section{Legal and Ethical concerns of Medical Tourists visiting India:}

Although medical tourism in India offers significant cost savings to U.S. patients, it comes with increased risk to them (Van Demark, 2007). There are concerns for the patients visiting countries, such as India, Thailand, or Malaysia have very different infectious disease-related epidemiology. Another consideration is the quality of post-medical care which can vary dramatically, depending on the hospital and country, and may be different from U.S. and European standards. A further risk factor relates to the resolution of litigation in the event of a problem. If U.S. patients receive medical care abroad that is less than satisfactory outcome, what recourse do they have? Of course, the patients could work through the host country legal system. However, this could be difficult and burdensome if the patients live far from the place they received medical treatment. If patients take the matter to U.S and Europian courts, the lawsuit will not commence until the defendant is served with a summons and complaint. Service can be facilitated if there are any treaties, conventions or international agreements between U.S. and the country where treatment occurred, but not all countries are signatories to such international agreements. Even if the countries have some form of agreement for cooperation in civil litigation, serving a summons and complaint on the healthcare providers may be difficult, expensive and extremely time consuming (Entin Feb. 2008).

The foreign hospitals or medical care providers which are located outside U.S. and have no offices or employees in the state where the suit is filed can easily challenge the U.S. court jurisdiction. Even if the court finds that "minimum contracts" exist, a defendant physician or hospital can argue that the exercise of personal jurisdiction may be unreasonable or unfair (Entin Feb. 2008). Even some U.S. states, such as Illinois, Idaho, Washington and New Jersey, have refused to exercise personal jurisdiction when patients traveled to one state to seek medical care and then sued in another state for compensation. Thus, patients who are thinking about medical tourism must be clear that limited compensation in the event of an unsatisfied outcome is one of the tradeoffs for going abroad for medical care.

Privacy Concerns: Privacy protection is another legal issue. The U.S. privacy law for the protection of health information is the Health Insurance Portability and Accountability Act (HIPAA). HIPAA protects health information that is "individually identifiable" or that can be tied to the subject of the information. HIPAA does not apply to medical information obtained outside the U.S. Thus, the security of patient's medical information would be at greater risk. On the other hand, when someone who needs medical care in the United States from someone, who is not his/her usual medical provider, may find that HIPAA may adversely impact the sharing of medical information unless it is clear that the subject of the information has authorized its disclosure (Bentley \& Bourque 2008). Therefore, patients should take complete medical records when they travel abroad seeking medical care. If not, the sharing of medical information for medical treatment will be difficult. Another ethical issue in medical tourism involves illegal organ transplants. The illegal purchase of organs and tissues for transplantation is very rampant in some developing countries. This is one reason that why medical tourism grows rapidly in some countries. Currently, many Indian cities have become hubs for kidney transplants, despite a 1994 nationwide ban on human organ sales (the Transplant of Human Organ Act states only relatives of patients can donate kidneys). So many patients, mainly foreigners, seeking kidney transplants have stimulated the demand for illegal organ transplants. The British transplantation Society said that "an accumulating body of 
evidence suggests that the organs of executed prisoners are being removed for transplantation without the prior consent of either the prisoner or their family". Many patients travel to China seeking kidney or liver transplants because of the shortages of donor organs in their own country. Most patients come from Japan and Korea.

Treatment based on embryonic stems, not available in the US, can sometimes be obtained legally or illegally in some foreign locations.

\section{Future of Medical Tourism in India:}

"The primary reasons as to why medical tourism would flourish in India include much more lower medical costs for various ailments such as bone narrow transparent, bye-pass surgery, knee surgery and liver transplant as compared to western countries". As a result of higher and very expensive medical costs in Western countries, patients from economies of scale and even blocs like Africa, Gulf and various Asian countries have started exploring medical treatment in hospitals located in various well-to do places in India. This is because its' medical infrastructure has geared up to provide them non-subsidized medical treatment at much lower costs, adds Mr. Jindal. The other reasons as to why, India would emerge as a lead hub for excellent medical treatment is because of its strength of highly qualified medical professionals and even equally higher qualities of availability of nurses. India has over 7,5 lakh qualified doctors and numbers of qualified nursing graduates and diploma holders are equally good and of high professional caliber who are content and satisfied with reasonable professional fees (ASSOCHAM, India). The economic recession has had a significant negative effect on the medical tourism industry. The total number of U.S. patients who went abroad seeking medical care declined from 750,000 in 2007 to 540,000 in 2008. An increase of transportation costs may be another factor contributing to the decline in U.S. patients traveling for care and rate at which foreigners are traveling to the U.S for medical care (Deloitte 2009). Recently, the weakening dollar probably causes many U.S. patients to reconsider plans to travel abroad for medical care. For example, in 2005 a patient who has been considering cosmetic surgery in Thailand received a price quote of 110,000 baht, equal to $\$ 2,683$ at that time $(12 / 14 / 2005$ exchange rate $=$ 41.005 baht per dollar). If patients decided to delay having surgery for two years, she was shocked to realize that her procedure would cost $\$ 3,625$ in 2007 (12/14/2007 exchange rate $=30.349$ baht per dollar). Although the surgery provider has not increased the price, the patient has to pay almost one thousand dollars more than two years prior because of the exchange rate fluctuation (Horowitz, 2008). The prospective impact of the recent U.S healthcare legislation has to be also evaluated. Some analysts believe that the objective of providing healthcare at "lower costs" has not been addressed. According to some, the legislation not only doesn't lower costs, but has a huge chance to significantly increase the already high cost for healthcare in America. Thus, healthcare costs will continue to rise and continue to become even more unaffordable than before. This would present a huge opportunity for medical tourism, and the passing of this legislation could lead to even greater adoption of medical tourism as one of the only ways to reduce healthcare costs (Stephano \& Edelheit 2009)

\section{Conclusion:}

Though the economic recession has caused a temporary slowdown in the growth of medical tourism, the industry is still young in India. India has various advantages like cost, no waiting period, English speaking staffs, Ayurveda, naturopathy and foreign trained doctors/nurses. Many legal, regulation, and ethical issues are being addressed and resolved by governments and medical institutions. As long as differences in medical techniques and costs exist among countries, medical tourism should continue to develop and evolve India as sought after destination. Government of India, ministry of tourism has set up a section called Marketing development assistance (MDA) and Medical Visa (M-visa) for promoting the patient arriving for Medical Tourism. Tourism ministry of India conducts road shows among potential countries to uphold India as Global Medical Tourism destination.

[2]. Medical Tourism in India by Raj Pruthi, Arise Publication

[3]. Chopra, Anuj, "Organ-transplant black market thrives in India," San Francisco Chronicle, Feb.9, 2009

[4]. Deloitte Center for Health Solutions, Medical tourism: Update and implications, 2009.

[5]. Indian Medical care- http//www.indiamedicalcare.com

[6]. Ehrbeck, Tilman, Ceani Guevara, and Paul D. Mango, "Mapping the market for medical travel",

[7]. http://www.health-tourism.com/medical-tourism/history/

[8]. Gahlinger, P.M. The Medical Tourism Travel Guide: Your Complete Reference to Top-Quality, Low-Cost Dental, Cosmetic, Medical Care \& Surgery Overseas. Sunrise River Press, 2008.

[9]. Gasparoni, Lourdes, "Planning Your Medical Trip Abroad: Recovery Retreat of Hotel," Medical Tourism, December 2007.

[10]. Gustafson, Sven. "Medical tourism could prove a challenge for Michigan hospitals," Aug. 6, 2009.

[11]. Mattoo, A. and Rathindran R. "Does Health Insurance Trade Impede Trade in Healthcare Services? World Bank Policy Research

[12]. www.bhratbook.com 